\title{
Avaliaçáo da Produtividade do Processo de Soldagem MAG por Simulação com o Método de Hipercubo Latino
}

\author{
José Luiz Ferreira Martins ${ }^{1}$ \\ Miguel Luiz Ribeiro Ferreiral
}

\begin{abstract}
Resumo: O objetivo deste trabalho é o estudo da viabilidade da utilização do Método de Simulação pelo Hipercubo Latino na estimativa da produtividade do processo de soldagem elétrica MAG em obras de montagem de tubulaçóes industriais com base em pequenas amostras. $\mathrm{O}$ estudo foi realizado a partir da análise de dados históricos em obras realizadas na REDUC (Refinaria Duque de Caxias - Estado do Rio de Janeiro - Brasil), onde foi utilizado o software ControlTub 5.3 na coleta dos dados. A partir desta base de dados foram retiradas para análise pequenas amostras aleatórias, considerando cada uma delas como se o restante do conjunto amostral fosse desconhecido Nas pequenas amostras foram realizadas simulaçóes com o Método do Hipercubo Latino. As simulaçóes são realizadas no ambiente de programação do MAthWorks e do BestFit. Comparando-se os resultados da amostra com 52 elementos e os dados gerados por simulação com base nas pequenas amostras observa-se a viabilidade da aplicação do Método de Simulação Hipercubo Latino na estimativa da produtividade na soldagem de tubulações industriais com o processo MAG. É apresentada, também, uma ferramenta de avaliação da produtividade em tempo real, possibilitando ajustes nas estimativas e monitoração da produtividade durante a realização das atividades previstas, possibilitando a avaliação não somente na conclusão da obra, o que é uma prática atual da indústria. A utilização da simulação com o método de Hipercubo Latino apresenta desdobramentos que permitem a adoção de critérios, tais como, produtividade otimista, média e pessimista.
\end{abstract}

Palavras chave: Produtividade, Simulação, Hipercubo Latino, Soldagem MAG

\begin{abstract}
This paper deals with the analysis of the viability using the Latin Hypercube Sampling Simulation Method to measure the productivity in the industrial MAG welding piping based on small samples. The study was conducted by analyzing a sample collected in works made in Duque de Caxias Refinery (REDUC), in Rio de Janeiro, Brazil. The ControlTub 5.3 software was used for data acquisition and in the simulation it was used the Mathworks and the BestFit program environment. The data analyses of the obtained results were compared using the proposed simulation method, demonstrating its applicability. It also presents an assessment tool productivity in real time, allowing for adjustments in estimates of productivity and monitoring during the performance of the enterprise, enabling its evaluation not only in completing the work, which is the current industry practice. These results demonstrated the feasibility in applying the method of Latin Hypercube Sampling in estimating productivity considering the MAG welding process in industrial pipes assembly and the capacity to build some evaluation scenarios, like optimist, mean and pessimist productivity.
\end{abstract}

Keywords: Productivity, Simulation, Latin Hypercube Sampling, Welding, MAG. 


\section{INTRODUÇÃO}

Este trabalho faz parte de uma série de pesquisas relacionadas à identificaçáo da produtividade em processos de soldagem elétrica por simulação. A amostra de referência apropriada é composta de dados de juntas soldadas com o processo de soldagem elétrica MAG em tubulações industriais de aço carbono. A escolha deste processo de soldagem deve-se ao fato de que o mesmo tem uma versatilidade na utilização, inclusive com capacidade de automatização. Em linha de pesquisa idêntica, foi verificada a aplicabilidade dos Métodos de Simulação por Monte Carlo (Martins et. al., 2011) e Hipercubo Latino (Martins e Ferreira, 2011) no processo de soldagem elétrica por eletrodo revestido, bem como a comparação entre estes dois métodos de simulação neste processo de soldagem (Martins et. al., 2012). A metodologia adotada neste trabalho com a utilização da Simulação por Hipercubo Latino é semelhante à utilizada por Martins e Ferreira (2011). Assim, o objetivo deste trabalho é ampliar o conhecimento da aplicabilidade dos métodos de simulação em processos de soldagem, bem como, avaliar a aplicabilidade do Método de Simulação Hipercubo Latino (Latin Hypercube Sampling - LHS) na estimativa da produtividade na soldagem de juntas soldadas com o processo MAG através das informaçôes fornecidas por avaliação de pequenas amostras. A amostra de referência tem como base os dados históricos coletados por Gioia et. al. (2009), de onde foram retiradas amostras aleatórias, com reposiçáo, considerando cada uma delas como se os dados restantes do conjunto amostral fossem desconhecidos. A partir de cada pequena amostra são gerados dados virtuais através da simulação com Hipercubo Latino. Na seqüência, são geradas as funçóes de densidade de probabilidade (FDP) e de densidade acumulada (FPA). Comparando-se as curvas geradas com a obtida pelo conjunto de dados da amostra de referência, que representam o universo do parâmetro, avalia-se o grau de precisão da estimativa gerada pela simulação. Uma vez constatada a aplicabilidade deste método, obtém-se uma nova ferramenta para a monitoraçáo da produtividade em soldagem, na elaboração de estimativas de custos e de prazos em obras de montagem de tubulaçóes industriais.

\section{REVISÃO BIBLIOGRÁFICA}

Apresenta-se aqui a importância dos indicadores de produtividade e sua aplicação em processos de soldagem elétrica, bem como a síntese da aplicação do método do Hipercubo Latino para simulação

Nos métodos e processos utilizados na indústria da construção é necessária a introdução de recursos humanos, materiais e monetários, tendo como resultado um produto, Diekmann e Heinz (2001).

Classicamente, a produtividade é definida pela relação entre os recursos humanos e materiais utilizados para obtenção de um produto em tempo determinado. Assim, segundo Diekmann e Heinz (2001), a produtividade é a relação do homem-hora $(\mathrm{Hh})$ utilizado no processo de conversão construtiva com a quantidade de produtos obtidos. Os referidos autores apresentam a definição do Homem-hora representada pelo trabalho do trabalhador em uma hora de trabalho. Sendo esta relação utilizada pela indústria.

No caso da soldagem, a produtividade é, de forma geral, a quantidade de metal de solda depositado em relaçáo à quantidade de recursos humanos consumidos na soldagem. Nos processos de soldagem elétrica MAG, a produtividade é a relação entre o volume, em $\left[\mathrm{cm}^{3}\right]$ ou a massa depositada $[\mathrm{kg}]$, pelo $[\mathrm{Hh}]$ utilizado no processo de soldagem. Assim, a unidade utilizada é $\left[\mathrm{cm}^{3} /\right.$ $\mathrm{Hh}]$, ou $[\mathrm{kg} / \mathrm{Hh}]$.

Considerando a monitoração da produtividade na soldagem são mencionados na literatura vários indicadores. Existem os indicadores que consideram somente a deposição com o arco aberto e os que consideram o tempo de execução total da junta, sendo que estes últimos são os mais usados na indústria; conforme evidenciado em PROMINP (2010), elaborado com a participação da indústria de construção e montagem nacional, onde são estabelecidos, entre outros, padrões para indicadores de produtividade de soldagem. Outros trabalhos importantes sobre índices de produtividade em soldagem mencionados na literatura abordam a importância deste tipo de indicadores. São destacadas aqui as consideraçóes de Page e Nation (1967), que realiza uma abordagem abrangente sobre a utilização do Homem-hora em diversas conjunturas e situaçóes de soldagem; a AWS (2002) estabelece oito tipos de medida ge- 
rais de produtividade e Brito e Paranhos (2005) aborda a dependência do processo de soldagem na produtividade, nos diversos métodos e processos utilizados na indústria.

A maioria dos indicadores que consideram o tempo de execução total da junta relaciona o volume de solda, normalmente expresso em $\left[\mathrm{cm}^{3}\right]$, ou massa depositada, geralmente expressa em quilogramas $[\mathrm{kg}]$, considerados em relação à quantidade de Homens-hora (Hh) consumida na operação de soldagem. Quanto à mão-de-obra, são encontradas as seguintes condiçôes: quantidade de Hh somente dos soldadores; quantidade de Hh dos soldadores mais ajudantes e; quantidade de Hh dos soldadores, ajudantes e supervisáo de soldagem no nível mais baixo, que, normalmente, é intitulado de encarregado de solda pela indústria brasileira.

Os indicadores utilizados neste artigo têm como base os dados históricos levantados por Gioia et. al. (2009), em que consta a produtividade de cada sinete de soldador, em determinado número de dias trabalhados, a qual é expressa em $\left[\mathrm{cm}^{3} / \mathrm{Hh}\right]$. Sendo que, o sinete é uma nomenclatura alfanumérica atribuída a cada soldador envolvido no processo para registro e apropriação. As mediçóes de tempo para avaliação da equivalência das medidas foram realizadas em obra com a permissão da empresa e considerando a situação real de obra, em que o soldador tem suas necessidades vinculadas ao ambiente de trabalho. A mão de obra considerada na obtenção dos indicadores leva em conta as atividades de soldagem exercidas pelo soldador. Para a medida da produtividade é considerado que o início da contagem do tempo deve ser o início da soldagem da junta e o término deve ocorrer no encerramento da soldagem, contabilizados todos os tempos intermediários envolvidos no processo.

\section{HIPERCUBO LATINO}

O Método de Hipercubo Latino, "Latin Hypercube Sampling” (LHS), é um método de simulação que tem como base a geração de uma quantidade de números pseudo aleatórios previamente estabelecidos, com seus valores distribuídos proporcionalmente pelos estratos quantificados, de forma semelhante ao método de Monte Carlo, pela Regra de Sturges (Morano e Ferreira, 2003a). A função de distribuição de cada estrato apresenta seus parâmetros identificados a partir de critérios de avaliação de sua aderência em relação à distribuição dos elementos em cada estrato da amostra.

Pilger et. al. (2005) realiza uma abordagem profunda sobre os métodos de simulaçáo e o aumento da sua eficiência, apresenta a proposta de substituição do método de Monte Carlo pela técnica de "Latin Hypercube Sampling" (LHS) considerando a maior precisão e rapidez que o método fornece para todo modelo de incerteza.

Maschio et. al. (2009) apresenta a aplicação da técnica de Hipercubo Latino na integração do ajuste de histórico de produção com a análise de incertezas com vista a modelos mais confiáveis para a previsão de produção de petróleo e gás.

A função geratriz a ser utilizada em cada estrato é a FDP do tipo Normal. Desta forma, os vetores que contém os parâmetros da média e do desvio padrão, em que cada elemento do vetor representa cada estrato, são utilizados na geração da matriz de números pseudo aleatórios definidos de forma proporcional ao percentual de elementos de cada estrato da amostra, formada por " $\mathrm{m}$ " colunas que representam os " $m$ " estratos da amostra e " $n$ " linhas que representam os números pseudo aleatórios gerados em cada estrato. No caso de não haver possibilidade de redução do número de estratos para evitar a ocorrência em algum estrato da amostra sem, pelo menos, um elemento, considera-se o valor médio do intervalo do estrato, na posição correspondente do vetor das médias e desvio padrão igual a zero na posição correspondente do vetor de desvio padrão.

A quantidade de números pseudo aleatórios a serem gerados para a simulaçáo são estabelecidos de acordo com as recomendaçóes fornecidas em Cochran (1954), Triola (1999), Flanagan e Norman (2003) e Morano e Ferreira (2003b), que mostram indicações de boas técnicas na avaliação da quantidade de 1000 números pseudo aleatórios, com vista a que haja aderência entre a simulação realizada e a pequena amostra utilizada para tal, através de teste qui-quadrado. Com a aprovação neste teste considera-se satisfeita a condição de aderência, ou seja, a simulação é considerada válida para a estimativa de produtividade em análise. Em seguida, encerra-se a análise pela avaliação dos seus resultados e a geraçáo dos diagramas de representação das FDP e das FPA correspondentes, que servem de base para o estabelecimento da variação na produtividade. 


\section{PROCEDIMENTO EXPERIMENTAL}

As etapas necessárias para a realização dos procedimentos do experimento foram conduzidas da seguinte forma: a- definir a amostra de referência que represente a população que se deseja fazer à estimativa; b- apropriar os elementos da amostra de referência; c- coletar as pequenas amostras extraídas da amostra de referência com reposição; d- estabelecer o nível de significância a ser adotado; e- calcular o número de estratos a ser utilizado; $\mathrm{f}$ - distribuir os dados da amostra pelos estratos; g- avaliar o percentual da quantidade de elementos em cada estrato h- estabelecer a quantidade de números pseudo aleatórios a serem gerados e em quantidade proporcional ao percentual correspondente a cada estrato da pequena amostra; $\mathrm{i}$ - calcular os vetores da média e do desvio padráo da amostra; $\mathrm{j}$ - avaliar a FDP da pequena amostra pela união dos pontos centrais do intervalo de cada estrato; $\mathrm{k}$ - realizar a simulaçáo com a geração dos respectivos números pseudo aleatórios; 1 - contar a quantidade de elementos em cada estrato da simulaçáo; $m$ - realizar o teste de aderência pelo teste de qui quadrado da simulação em relação a amostra; $\mathrm{n}$ - validação da hipótese $\mathrm{H}_{0}$, em que o valor calculado deve estar a baixo do valor máximo do qui quadrado; o - retornar ao inicio por eventual náo aderência da simulação à pequena amostra, em caso contrário, construção da FPA e geração de gráficos das principais funções que definem as características da amostra, da simulação e comparaçóes entre elas.

$\mathrm{Na}$ interpretação da apresentação da variação da produtividade, avalia-se que ela é crescente quanto maior for a quantidade de $\left[\mathrm{cm}^{3}\right]$ produzidos por Homem-hora, ou, paralelamente, a produtividade será decrescente, pela maior quantidade de Homem-hora utilizada na quantidade de $\left[\mathrm{cm}^{3}\right]$ produzida. Esta observação se justifica pela possibilidade de se avaliar a produtividade ou a improdutividade, dependendo das condiçóes de análise que se necessite adotar.

\section{AMOSTRA DE REFERÊNCIA E PEQUENAS AMOSTRAS}

Para o experimento utilizou-se a base de dados de Gioia et. al. (2009) e Constâncio et. al. (2009). Na formação da amostra de referência, com 52 elementos, não se considerou a apropriação mínima de 10 dias efetivamente trabalhados, devido a que a amostra disponível não dispunha de condiçốes para tal. Assim, todas as pequenas amostras contêm informaçóes sobre as condiçóes de aprendizado inerentes ao processo, (Anzanello e Fogliato, 2007), ou seja, a amostra de referencia apresenta informaçóes sobre os ajustes das atividades até alcançar o valor de regime inerente ao procedimento. Nestas condiçóes leva-se em consideração que na prática operacional é percebido que um soldador com dez dias de atividade efetiva está em boa condição de produtividade e sem a influência do efeito do aprendizado, (Martins e Ferreira, 2011), o que não foi possível resgatar na amostra disponível.

Os elementos da base de dados foram obtidos em obras na Refinaria de Duque de Caxias (REDUC), Rio de Janeiro, Brasil, em que as mediçóes foram realizadas pela contratada, verificadas pela fiscalização e validadas com a utilização do software ControlTub 5.3.

Os valores coletados são apresentados na forma de valores médios diários dos indicadores de produtividade para cada soldador com atividade no campo de duas empresas prestadoras de serviços. Os elementos coletados foram introduzidos no software com cada soldador representado por um sinete, em que é atribuída uma numeração para cada indivíduo. Estes indicadores são coletados em junta equivalente [Juequi], tratados e convertidos para volume de solda depositada em junta de topo, por homem hora $\left[\mathrm{cm}^{3} / \mathrm{Hh}\right]$, na montagem de tubulação no campo. Assim, a amostra de referência é composta de 52 valores disponíveis, com produtividade média medida em $\left[\mathrm{cm}^{3} / \mathrm{Hh}\right]$, para a identificação do comportamento do processo.

Com a amostra de referência definida, são coletadas dela três pequenas amostras compostas de 20,15 e 10 elementos, coletadas de forma aleatória, uma a uma, com reposição a cada coleta. As amostras, assim coletadas, são nomeadas de 52elMAG para a amostra de referência com 52 elementos, 20elMAG, para a pequena amostra composta com 20 elementos, 15elMAG para a pequena amostra com 15 elementos e 10elMAG para a pequena amostra com 10 elementos.

\section{FUNÇÃO GERATRIZ E ESTRATOS}

No método para simulação por LHS, divide-se cada pequena amostra em estratos e consi- 
dera-se a quantidade de elementos neles contidos. Estes elementos representam uma proporção em relação ao total da amostra e cada estrato é representado por sua média e desvio-padrão ou máximo e mínimo, dependendo da distribuição utilizada em cada estrato. Neste trabalho, utiliza-se como geratriz a função Normal.

Para o estabelecimento do número de estratos, utiliza-se o mesmo critério para a definição das classes, em conformidade com Morano e Ferreira (2003a). Assim, para elaboração dos histogramas é utilizado o critério de Sturges para o estabelecimento do número estratos, que são considerados de forma idêntica ao que é considerado parta as classes. No estabelecimento da quantidade de números pseudo aleatórios foram adotadas as recomendaçóes de Cochran(1954), Flanagan e Norman (2003), Morano e Ferreira (2003a) e Martins e Ferreira (2011). Desta forma, com os estratos definidos e seus respectivos valores médios, é possível visualizar a FDP e a FPA de cada amostra e, a partir daí, pode ser dado início ao processo de simulaçãa.

\section{SIMULAÇÃO DAS AMOSTRAS}

A estruturação dos números pseudo aleatórios gerados na simulação com o método de LHS foi distribuída nos seguintes passos: a) Em cada pequena amostra considerada, é calculado para cada estrato o valor médio, a quantidade de elementos, a média e o desvio-padrão, nos estratos em que não haja nenhum elemento, a média e o desvio-padrão são considerados como o valor médio do estrato e zero respectivamente, esta condição deve ser evitada com a reduçáo do numero de estratos, se for possível; b) Com a quantidade de elementos em cada estrato é calculado o valor percentual correspondente, desta forma, é possível visualizar a FDP e a FPA da amostra; c) O vetor dos valores percentuais equivalentes de elementos pertencentes a cada estrato estabelece a distribuição percentual dos números pseudo aleatórios a ser gerada em cada estrato correspondente; a forma da distribuição utilizada para gerar estes números, em cada estrato, é do tipo normal e está estruturada em conformidade com MAthWorks (2001, 2007); d) Definido o número de elementos da simulação, ela é acionada e são gerados os números pseudo aleatórios correspondentes a cada estrato; e), com os dados gerados é identificada a FDP e a FPA da simulação realizada; f) Neste momento é necessário realizar um teste de aderência dos dados da simulaçáo com os dados da amostra, os testes que podem ser realizados são o teste de qui-quadrado e/ou o teste da máxima verossimilhança relativa da simulação e da amostra; g) Aprovada a aderência da simulação em relação à amostra, é calculada a inferência estatística da simulação.

Paralelamente, são gerados gráficos das simulaçóes, em comparaçáo com a amostra de referência. Pode-se assim, analisar a produtividade do processo em diferentes cotas percentuais, pela observação das FPA das simulações das pequenas amostras.

\section{RESULTADOS OBTIDOS}

Os resultados obtidos na análise das pequenas amostras 20elMAG, 15elMAG e 10elMAG, bem como, da amostra de referência com 52elMAG são apresentadas a seguir.

\section{AMOSTRA DE REFERÊNCIA 52ELMAG}

A análise da amostra de referência 52elMAG, contendo 52 elementos, resultou na estatística apresentada pela Tabela 1 .

Tabela 1: Estatística de 52elMAG

\begin{tabular}{|c|c|}
\hline Estatística & Amostra $\left[\mathrm{cm}^{3} / \mathrm{Hh}\right]$ \\
\hline Máximo & 207.20 \\
\hline Mínimo & 0.84 \\
\hline Média & 40.81 \\
\hline D Padrão & 46.23 \\
\hline Mediana & 18.85 \\
\hline Moda & 3.97 \\
\hline Coef Variação & 1.13 \\
\hline Esperança & 40.9040 .71 \\
\hline
\end{tabular}

Na Figura 1 é mostrada a distribuição dos elementos desta amostra, distribuídos em quartis. Desta forma, observa-se a caixa contendo o primeiro quartil, a mediana na linha do bigode e o terceiro quartil. Pela observaçáo nesta figura, pode-se afirmar que $75 \%$ dos valores da amostra apresentam produtividade abaixo de $80 \mathrm{~cm}^{3} / \mathrm{Hh}$. Observaçóes semelhantes podem ser obtidas para valores até $50 \%$ e até $25 \%$. 


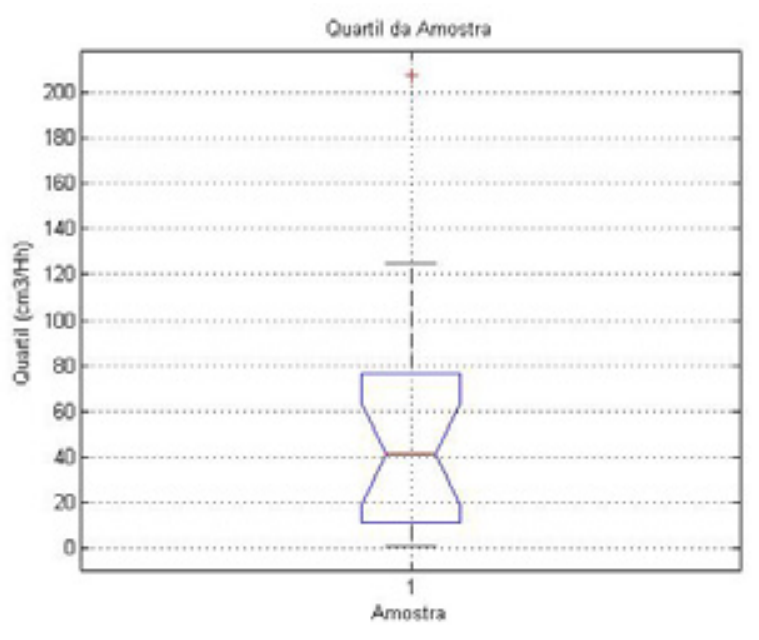

Figura 1: Representação em quartis da Amostra 52elMAG

Na Figura 2 são mostradas as representaçóes da FDP e a FPA da amostra de referência 52elMAG. Os valores apresentados representam o valor médio de cada estrato.

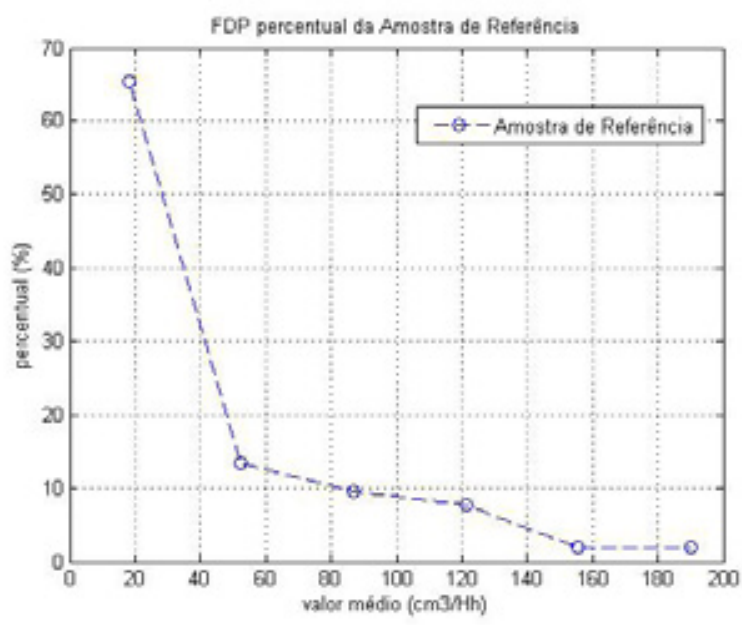

Figura 2a: FDP de 52elMAG

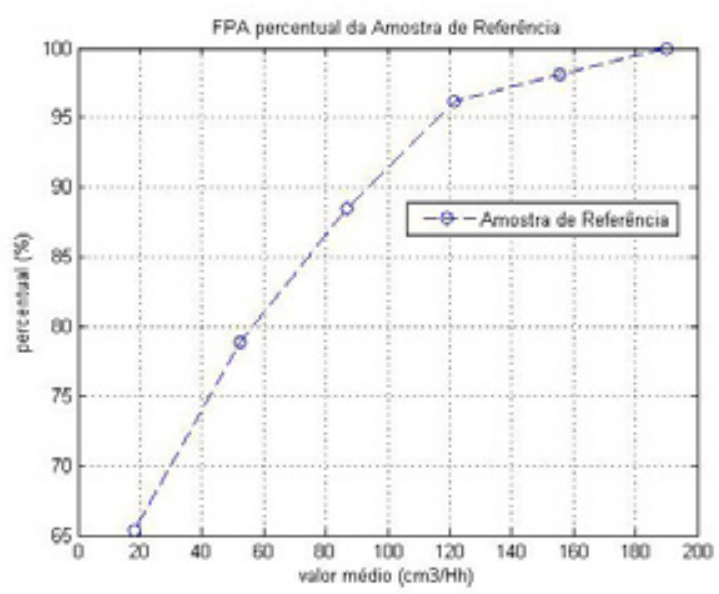

Figura 2b: FPA de 52elMAG
Esta amostra de referência retrata o comportamento do processo em análise. As simulações das amostras menores devem apresentar comportamento semelhante para haver representatividade destas no processo.

$\mathrm{Na}$ Figura $2 \mathrm{~b}$ observa-se que a produtividade na cota de $100 \%$, do processo de soldagem, é de $190 \mathrm{~cm}^{3} / \mathrm{Hh}$. A produtividade nas cotas de $95 \%$ e $90 \%$ são, respectivamente, de 115 e $95 \mathrm{~cm}^{3} / \mathrm{Hh}$.

Assim, tem-se a referência básica do comportamento da produtividade do processo para um dimensionamento mais adequado da mão de obra a ser utilizada.

Realizando a análise da FDP que melhor se adapta a esta amostra, pelo BestFit (2004), verifica-se que é a função Pearson5, com a forma apresentada na Figura 2c e as características apresentadas pela Tabela 2

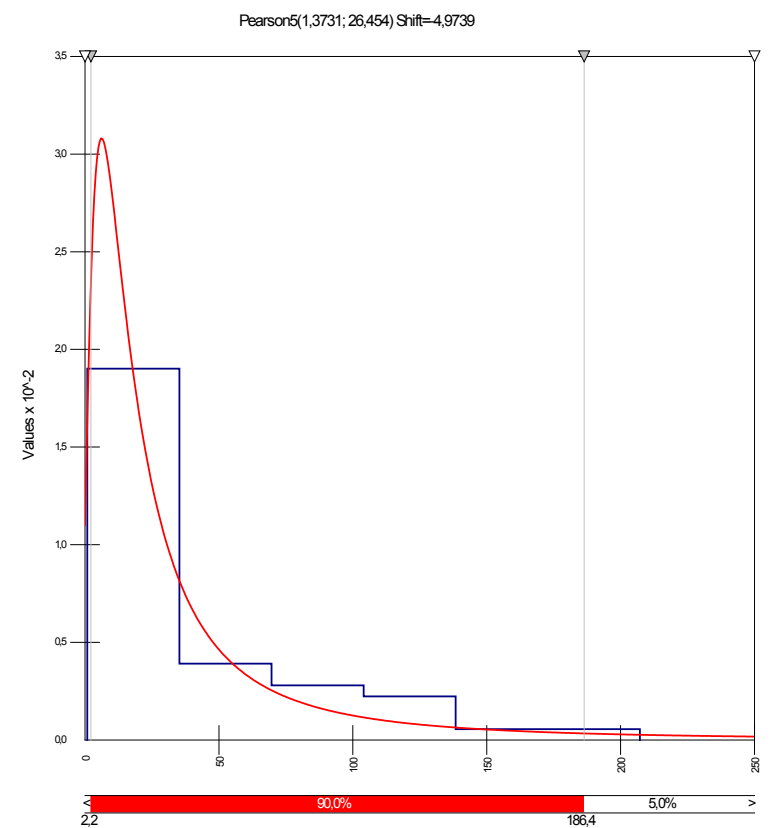

Figura 2c: FDP ajustada pelo Programa BestFit de 52elMAG

Tabela 2: Parâmetros da Função Pearson 5 de 52elMAG

\begin{tabular}{|c|c|}
\hline Parâmetro & Valor \\
\hline Máximo & $+\infty$ \\
\hline Mínimo & 0.84 \\
\hline Média & 65.92 \\
\hline D Padrão & 46.23 \\
\hline Mediana & 20.03 \\
\hline Moda & 6.17 \\
\hline
\end{tabular}




\begin{tabular}{|c|c|}
\hline Parâmetro & Valor \\
\hline Coef Variação & 0.70 \\
\hline a & 1.73 \\
\hline b & 26.45 \\
\hline
\end{tabular}

Tabela 4: Estatística de 20elMAG e respectiva simulação

\section{AMOSTRA 20ELMAG COM 20 ELEMENTOS}

A pequena amostra 20elMAG é retirada de forma aleatória da amostra de referência 52elMAG e é representada pela estatística apresentada pela Tabela 3. 20elMAG é divida em 6 estratos com a quantidade de elementos mostrados pela Tabela 3.

Na Figura 3 é mostrada a distribuição dos elementos desta amostra, distribuídos em quartis. Desta forma, observa-se a caixa contendo o primeiro quartil, a mediana na linha do bigode e o terceiro quartil. Pela observaçáo deste diagrama pode-se afirmar que $75 \%$ dos valores da amostra apresentam produtividade abaixo de $80 \mathrm{~cm}^{3} / \mathrm{Hh}$.

Tabela 3: Distribuição pelos estratos dos elementos da amostra 20elMAG

\begin{tabular}{|c|c|c|c|}
\hline $\begin{array}{c}\text { Valor Médio } \\
\text { do Estrato }\end{array}$ & $\begin{array}{c}\text { Quantidade } \\
\text { de elementos }\end{array}$ & $\begin{array}{c}\text { Quantidade } \\
\%\end{array}$ & $\begin{array}{c}\text { Quantidade } \\
\text { Acumulada } \\
\%\end{array}$ \\
\hline 18.07 & 10 & 50 & 50 \\
\hline 52.46 & 5 & 25 & 75 \\
\hline 86.85 & 3 & 15 & 90 \\
\hline 121.23 & 1 & 5 & 95 \\
\hline 155.62 & 0 & 0 & 95 \\
\hline 190.01 & 1 & 5 & 100 \\
\hline Total & 20 & 100 & \\
\hline
\end{tabular}

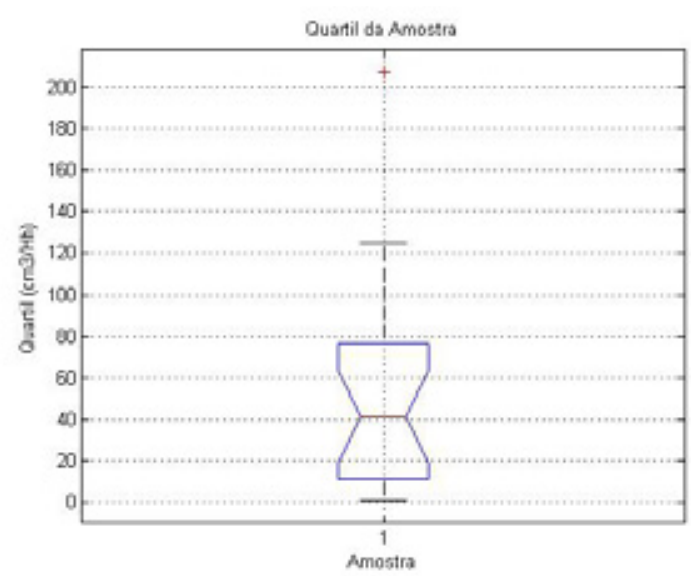

Figura 3: Representação em quartis de 20elMAG

\begin{tabular}{|c|c|c|}
\hline Estatística & Amostra $\left[\mathrm{cm}^{3} / \mathrm{Hh}\right]$ & LHS $\left[\mathrm{cm}^{3} / \mathrm{Hh}\right]$ \\
\hline Máximo & 207.20 & 207.20 \\
\hline Mínimo & 0.88 & 0.00 \\
\hline Média & 52.07 & 51.17 \\
\hline D Padrão & 51.30 & 52.02 \\
\hline Mediana & 41.40 & 58.43 \\
\hline Moda & 6.20 & 125.00 \\
\hline Coef. Variação & 0.99 & 1.02 \\
\hline Esperança & 51.86 & 52.15 \\
\hline
\end{tabular}

Realizando a simulação pelo LHS, com uma quantidade de 1000 números pseudo aleatórios, divididos de forma proporcional ao percentual atribuído à distribuição dos elementos da amostra pelos estratos, obtém-se a estatística apresentada pela Tabela 4.

Esta simulação foi considerada válida devido ao teste qui-quadrado ter apresentado valor máximo abaixo do admitido.

A simulação da Amostra 20elMAG apresenta a quantidade de números pseudo aleatórios mostrada pela Tabela 5 .

Tabela 5: Distribuição pelos estratos da simulação de 20elMAG

\begin{tabular}{|c|c|c|c|}
\hline $\begin{array}{c}\text { Valor Médio } \\
\text { do Estrato }\end{array}$ & $\begin{array}{c}\text { Quantidade } \\
\text { de elementos }\end{array}$ & $\begin{array}{c}\text { Quantidade } \\
\%\end{array}$ & $\begin{array}{c}\text { Quantidade } \\
\text { Acumulada } \\
\%\end{array}$ \\
\hline 1.65 & 465 & 55 & 55 \\
\hline 39.02 & 35 & 25 & 80 \\
\hline 76.40 & 391 & 0 & 80 \\
\hline 113.77 & 59 & 10 & 90 \\
\hline 151.14 & 0 & 5 & 95 \\
\hline 188.52 & 50 & 5 & 100 \\
\hline Total & 1000 & 100 & \\
\hline
\end{tabular}

A representação da FDP da pequena amostra 20elMAG e respectiva simulação, com a comparação da diferença entre amostra e simulação são representadas na Figura 4. 


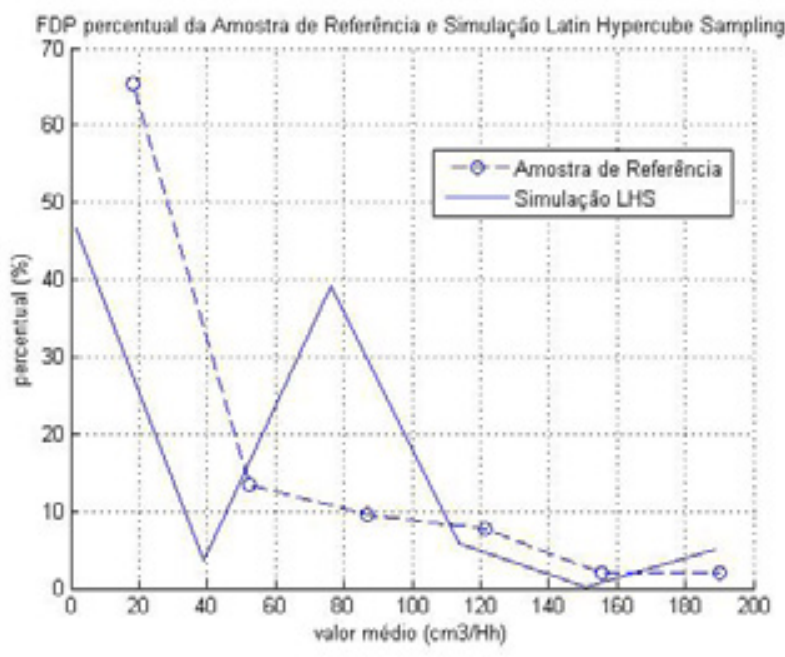

Figura 4a: FDP da amostra de referência e simulação LHS de 20elMAG

A representação da FPA da amostra 20elMAG e respectiva simulação, com a comparação da diferença entre amostra e simulação são representadas na Figura 5.

Observando-se a FPA da simulação, na Figura $5 \mathrm{a}$, pode-se afirmar que a produtividade limite $100 \%$ do processo de soldagem por eletrodo revestido é de $190 \mathrm{~cm}^{3} / \mathrm{Hh}$. A produtividade $95 \%$ e $90 \%$ são, respectivamente, de 115 e $80 \mathrm{~cm}^{3} / \mathrm{Hh}$. Observa-se que há uma grande diferença entre estas produtividades.

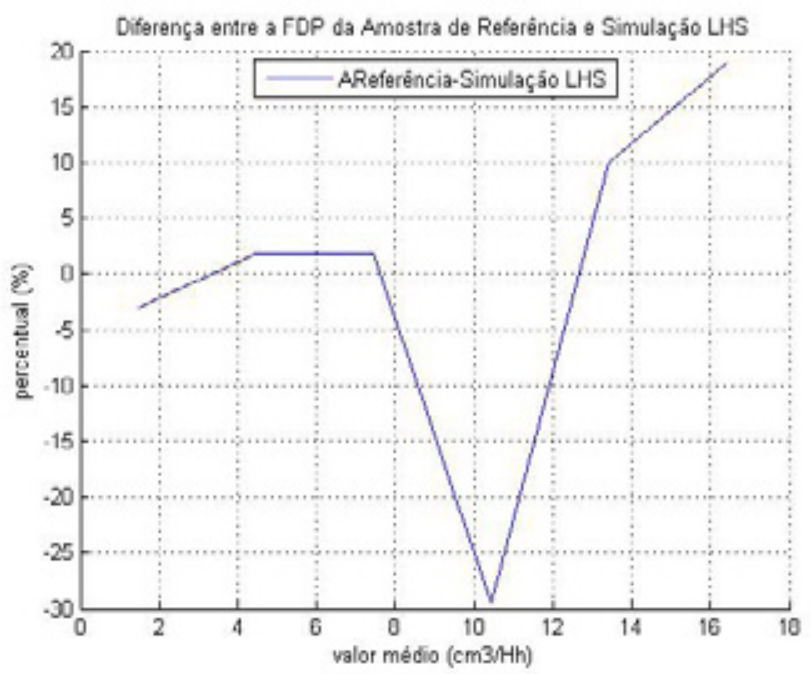

Figura 4b: Diferença na FDP de 52elMAG e simulaçáo LHS de 20elMAG

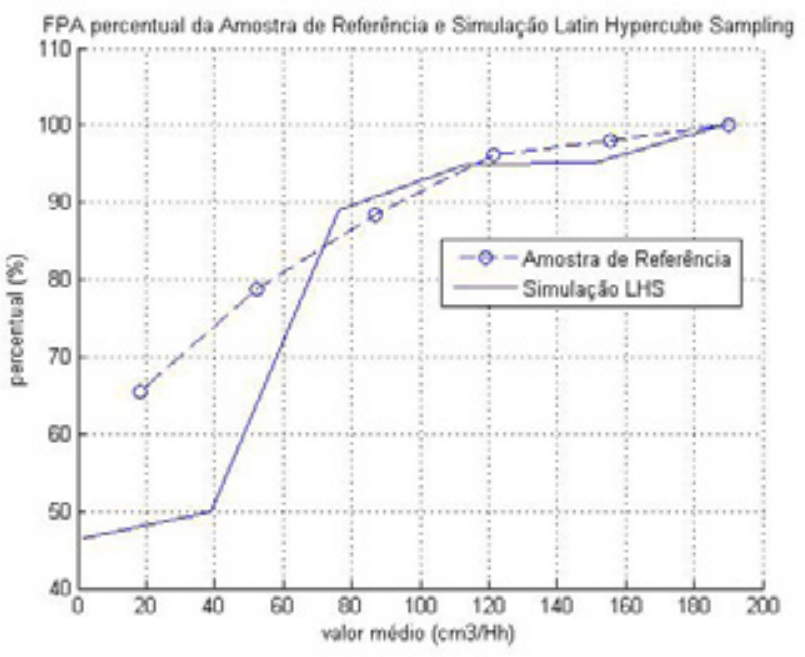

Figura 5a: FPA da amostra de referência e simulação LHS de 20elMAG

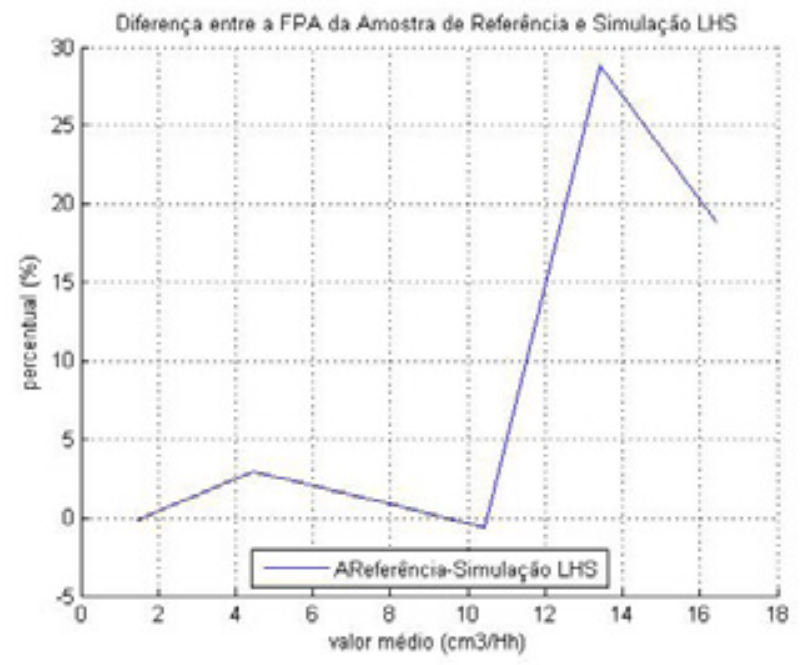

Figura 5b: Diferença na FPA de 52elMAG e simulação LHS de 20elMAG

Como observado na Figura 5b, os valores da amostra e da simulação apresentam uma diferença máxima de $30 \%$ na comparação entre o estrato 3 , da amostra de referência, com a simulação e uma variação de $17 \mathrm{~cm}^{3} / \mathrm{Hh}$.

\section{AMOSTRA 15ELMAG COM 15 ELEMENTOS}

A pequena amostra 15elMAG com 15 elementos, aleatoriamente escolhidos da amostra de referência 52elMAG, apresenta a estatística mostrada pela Tabela 6 . 
Tabela 6: Estatística de 15elMAG com 15 elementos e simulação

\begin{tabular}{|c|c|c|}
\hline Estatística & Amostra $\left[\mathbf{c m}^{3} / \mathbf{H h}\right]$ & LHS $\left[\mathbf{c m}^{3} / \mathbf{H h}\right]$ \\
\hline Máximo & 125.00 & 125.00 \\
\hline Mínimo & 3.97 & 0.00 \\
\hline Média & 42.31 & 43.23 \\
\hline D Padrão & 42.47 & 43.78 \\
\hline Mediana & 19.72 & 16.06 \\
\hline Moda & 3.97 & 0.00 \\
\hline Coef Variação & 1.00 & 1.01 \\
\hline Esperança & 42.34 & 40.71 \\
\hline
\end{tabular}

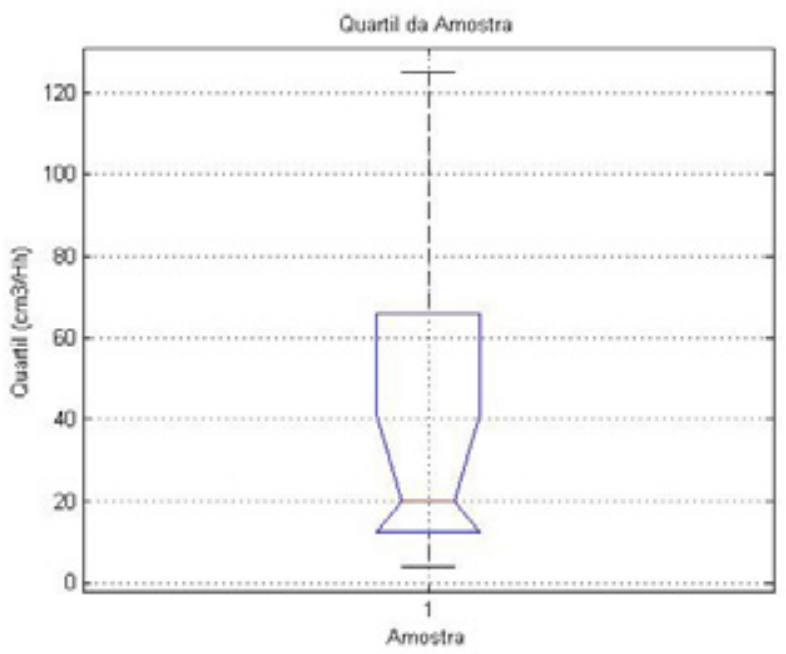

Figura 6: Representação em quartis da Amostra 15elMAG

Na Figura 6 é mostrada a distribuição dos elementos desta amostra, distribuídos em quartis. Desta forma, observa-se a caixa contendo o primeiro quartil, a mediana na linha do bigode e o terceiro quartil. Pela observaçáo deste diagrama pode-se afirmar que $75 \%$ dos valores da amostra apresentam produtividade abaixo de $65 \mathrm{~cm}^{3} / \mathrm{Hh}$.

Esta amostra é divida em 5 estratos com a quantidade de elementos mostrados pela Tabela 7.

Como nas amostras anteriores, realizando a simulação pelo LHS, com uma quantidade de 1000 números pseudo aleatórios, divididos de forma proporcional ao percentual atribuído a distribuiçáo dos elementos da amostra pelos estratos, obtém-se a estatística apresentada pela Tabela 6.
Tabela 7: Distribuição pelos estratos dos elementos da amostra 15elMAG

\begin{tabular}{|c|c|c|c|}
\hline $\begin{array}{c}\text { Valor Médio } \\
\text { do Estrato }\end{array}$ & $\begin{array}{c}\text { Quantidade } \\
\text { de elementos }\end{array}$ & $\begin{array}{c}\text { Quantidade } \\
\%\end{array}$ & $\begin{array}{c}\text { Quantidade } \\
\text { Acumulada } \\
\%\end{array}$ \\
\hline 16.07 & 8 & 53.33 & 53.33 \\
\hline 40.28 & 2 & 13.33 & 66.67 \\
\hline 64.49 & 2 & 13.33 & 80.00 \\
\hline 88.69 & 0 & 0.00 & 80.00 \\
\hline 112.90 & 3 & 20.00 & 100.00 \\
\hline Total & 15 & 100.00 & \\
\hline
\end{tabular}

Esta simulação foi considerada válida devido ao fato de que o teste de qui-quadrado ficou abaixo do valor máximo admitido.

A simulação da Amostra 15elMAG apresenta a quantidade de números pseudo aleatórios mostrada pela Tabela 8 .

Tabela 8: Estratos dos elementos da simulaçáo de 15 elMAG

\begin{tabular}{|c|c|c|c|}
\hline $\begin{array}{c}\text { Valor Médio } \\
\text { do Estrato }\end{array}$ & $\begin{array}{c}\text { Quantidade } \\
\text { de elementos }\end{array}$ & $\begin{array}{c}\text { Quantidade } \\
\%\end{array}$ & $\begin{array}{c}\text { Quantidade } \\
\text { Acumulada } \\
\%\end{array}$ \\
\hline 12.13 & 533 & 53.30 & 53.30 \\
\hline 37.21 & 133 & 13.30 & 66.60 \\
\hline 62.29 & 133 & 13.30 & 79.90 \\
\hline 87.38 & 1 & 0.10 & 80.00 \\
\hline 112.46 & 200 & 20.00 & 100.00 \\
\hline Total & 1000 & 100 & \\
\hline
\end{tabular}

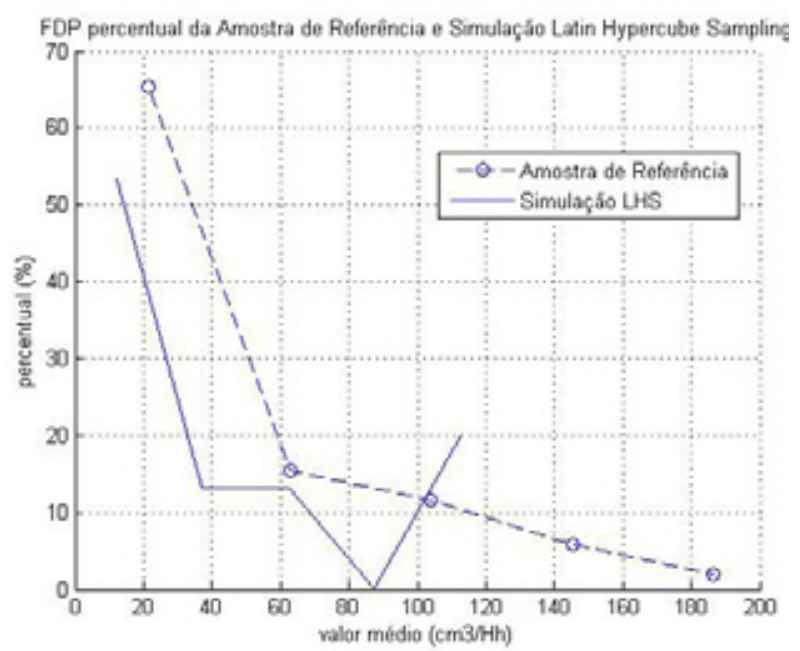

Figura 7a: FDP da amostra de referência e simulação LHS da amostra 15elMAG 
A representação da FDP da Amostra 15elMAG e respectiva simulação, com comparação da diferença entre amostra e simulação são representadas nas Figuras 7 a e $7 \mathrm{~b}$, respectivamente.

A representação da FPA da Amostra 15elMAG e respectiva simulação, com comparação da diferença nos estratos entre a amostra de referência e a simulação, são representadas na Figura 8.

$\mathrm{Na}$ Figura 8a, observando-se a FPA da simulação, pode-se afirmar que a produtividade limite $100 \%$ do processo de soldagem por eletrodo revestido é de $115 \mathrm{~cm}^{3} / \mathrm{Hh}$. A produtividade $95 \%$ e $90 \%$ são, respectivamente, de 105 e $100 \mathrm{~cm}^{3} /$ Hh. Neste caso, verifica-se um degrau, na cota de $80 \%$, que reflete uma condição relativa à adoção do valor médio do estrato correspondente, pois não houve elementos alocados neste estrato.

Assim, tem-se a referência básica do comportamento da produtividade do processo, para o dimensionamento mais adequado da mão de obra a ser utilizada.

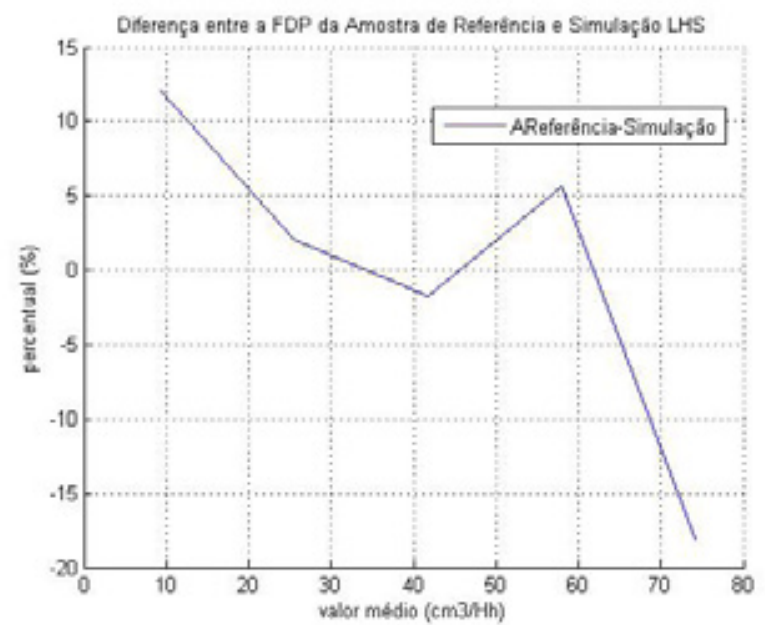

Figura 7b: Diferença na FDP de 52elMAG e simulação LHS de 15elMAG

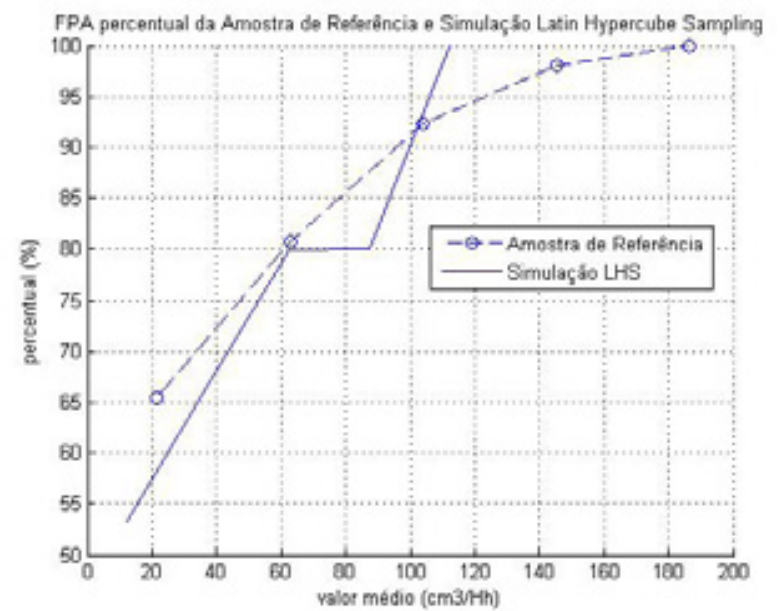

Figura 8a: FPA da amostra de referência e simulação LHS da amostra 15elMAG
$\mathrm{Na}$ Figura $8 \mathrm{~b}$ verifica-se que os valores da amostra e da simulação apresentam uma variação máxima com módulo em torno de $18 \%$ e uma variação de $75 \mathrm{~cm}^{3} / \mathrm{Hh}$.

\section{AMOSTRA 10ELMAG COM 10 ELEMENTOS}

A amostra com 10elMAG, com 10 elementos, retirada de forma aleatória da amostra de referência 52elMAG apresenta a estatística mostrada pela Tabela 9.

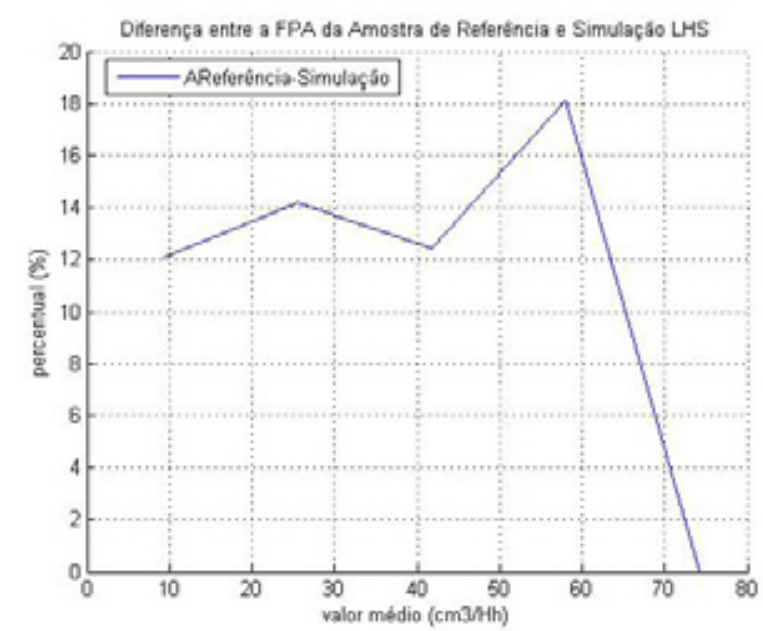

Figura 8b: Diferença na FPA de 52elMAG e simulação LHS de 15 elMAG

Tabela 9: Estatística da amostra 10el com 10 elementos e simulação

\begin{tabular}{|c|c|c|}
\hline Estatística & Amostra $\left[\mathrm{cm}^{3} / \mathrm{Hh}\right]$ & LHS $\left[\mathrm{cm}^{3} / \mathrm{Hh}\right]$ \\
\hline Máximo & 207.20 & 207.20 \\
\hline Mínimo & 5.95 & 1.76 \\
\hline Média & 62.04 & 63.60 \\
\hline D Padrão & 65.16 & 63.07 \\
\hline Mediana & 35.44 & 51.10 \\
\hline Moda & 5.95 & 51.10 \\
\hline Coef Variação & 1.05 & 0.99 \\
\hline Esperança & 61.9962 .00 & \\
\hline
\end{tabular}

$\mathrm{Na}$ Figura 9 é mostrada a distribuição dos elementos desta amostra distribuídos em quartis. Desta forma, observa-se a caixa contendo o primeiro quartil, a mediana na linha do bigode e o terceiro quartil. Pela observação deste diagrama pode-se afirmar que $75 \%$ dos valores da amostra apresentam produtividade abaixo de $100 \mathrm{~cm}^{3} / \mathrm{Hh}$. 
Esta amostra é divida em 5 estratos com a quantidade de elementos mostrados pela Tabela 10.

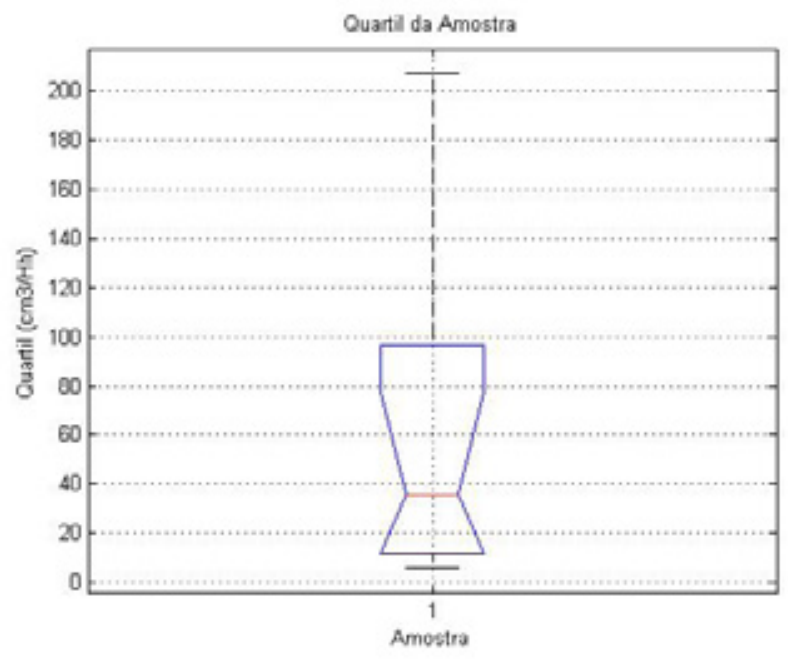

Figura 9: Representação em quartis da Amostra 10elMAG

Tabela 10: Distribuição pelos estratos dos elementos da amostra 10elMAG

\begin{tabular}{|c|c|c|c|}
\hline $\begin{array}{c}\text { Valor Médio } \\
\text { do Estrato }\end{array}$ & $\begin{array}{c}\text { Quantidade } \\
\text { de elementos }\end{array}$ & $\begin{array}{c}\text { Quantidade } \\
\%\end{array}$ & $\begin{array}{c}\text { Quantidade } \\
\text { Acum. } \%\end{array}$ \\
\hline 26.08 & 5 & 50 & 50 \\
\hline 66.33 & 1 & 10 & 60 \\
\hline 106.58 & 3 & 30 & 90 \\
\hline 146.83 & 0 & 0 & 90 \\
\hline 187.08 & 1 & 10 & 100 \\
\hline Total & 10 & 100 & \\
\hline
\end{tabular}

Como nas amostras anteriores, realizando a simulaçáo pelo LHS, com uma quantidade de 1000 números pseudo aleatórios, divididos de forma proporcional ao percentual atribuído à distribuiçáo dos elementos da amostra pelos estratos, obtém-se a estatística apresentada pela Tabela 9.

Esta simulação foi considerada válida devido ao fato de que o teste qui-quadrado ficou abaixo do valor máximo admitido.

A simulação da Amostra 10elMAG apresenta a quantidade de números pseudo aleatórios mostrada pela Tabela 11 .

A representação da FDP da amostra 10elMAG e simulação, com respectiva comparação da diferença entre a amostra de referência e a simulação são representadas na Figura 10.
Tabela 11: Estratos dos elementos da simulação de 10elMAG

\begin{tabular}{|c|c|c|c|}
\hline $\begin{array}{c}\text { Valor Médio } \\
\text { do Estrato }\end{array}$ & $\begin{array}{c}\text { Quantidade } \\
\text { de elementos }\end{array}$ & $\begin{array}{c}\text { Quantidade } \\
\%\end{array}$ & $\begin{array}{c}\text { Quantidade } \\
\text { Acumulada } \\
\%\end{array}$ \\
\hline 22.31 & 500 & 50.00 & 50.00 \\
\hline 63.39 & 100 & 10.00 & 60.00 \\
\hline 104.48 & 300 & 30.00 & 90.00 \\
\hline 145.57 & 1 & 0.00 & 90.00 \\
\hline 186.66 & 100 & 10.00 & 100.00 \\
\hline Total & 1000 & 100 & \\
\hline
\end{tabular}

A representação da FPA da Amostra 10elMAG e respectiva simulação, com a comparação da diferença entre amostra e simulação são representadas na Figura11.

Observando-se, na Figura 11a, a FPA da simulação pode-se afirmar que a produtividade limite $100 \%$ do processo de soldagem elétrica MAG é de $185 \mathrm{~cm}^{3} / \mathrm{Hh}$.

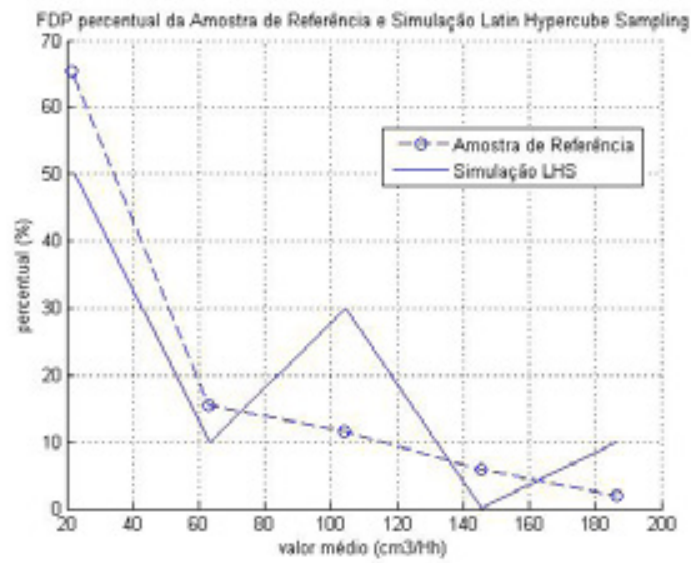

Figura 10a: FDP da amostra de referência e simulação LHS da amostra 10elMAG

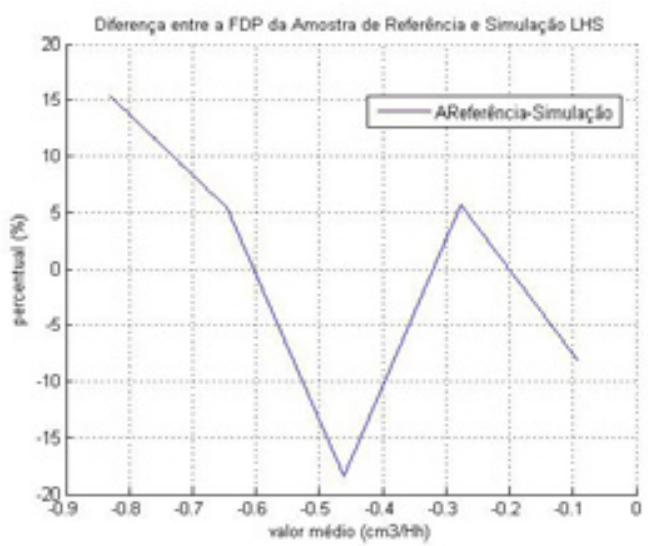

Figura 10b: Diferença na FDP de 52elMAG e simulação LHS de 10elMAG 


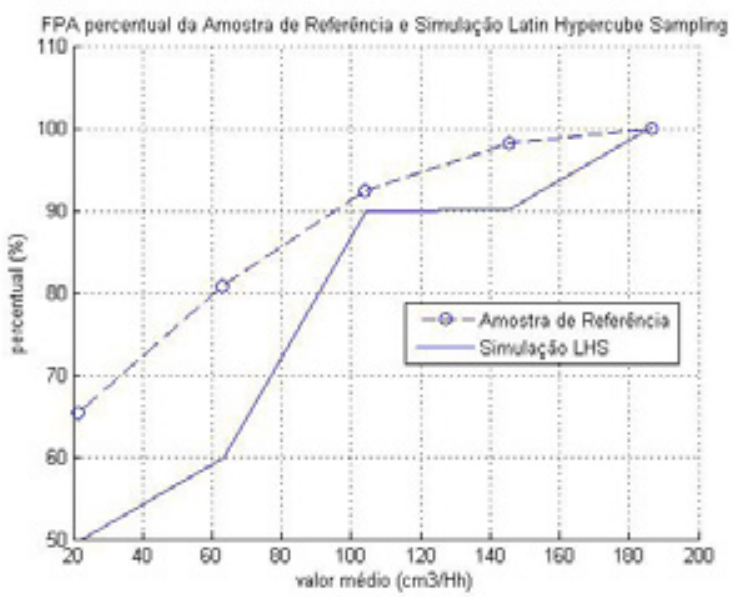

Figura 11a: FPA da amostra de referência e simulação LHS da amostra 10elMAG

A produtividade $95 \%$ e $90 \%$ são, respectivamente, de 160 e $105 \mathrm{~cm}^{3} / \mathrm{Hh}$. Assim, tem-se a referência básica da produtividade máxima possível do processo, para o dimensionamento mais adequado da mão de obra a ser utilizada.

$\mathrm{Na}$ Figura 11b mostra-se que os valores da amostra e da simulação apresentam uma variação máxima em torno de $20 \%$ e uma variação de 1 $\mathrm{cm}^{3} / \mathrm{Hh}$.

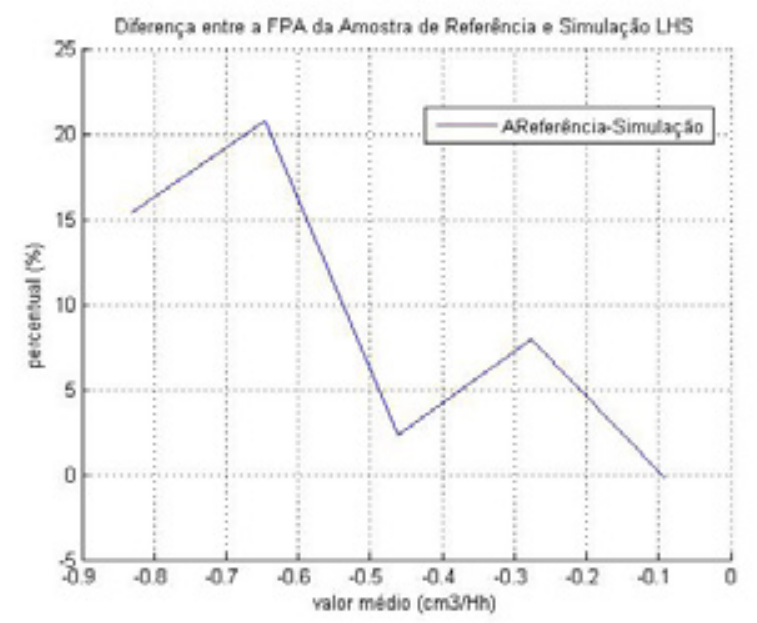

Figura 11b: Diferença na FPA de 52elMAG e simulação LHS de 10elMAG

\section{RESUMO DAS OBSERVAÇÓES}

As observações que são identificadas nas amostras analisadas podem ser resumidas em: a média e o desvio padrão do processo são de 40.81 $\mathrm{cm}^{3} / \mathrm{Hh}$ e $46.23 \mathrm{~cm}^{3} / \mathrm{Hh}$, respectivamente.

$\mathrm{Na}$ amostra de referência não houve possibilidade de retirar a influência da aprendizagem, elevando sensivelmente a dispersão do processo. De qualquer forma, considerando o objetivo deste trabalho, mostra-se que, independentemente da condição dispersiva no processo de soldagem MAG apresentado, as curvas das pequenas amostras apresentaram condiçóes de comparaçáo; e assim, de estimativa de produtividade, utilizando pequenas amostras.

Com relação à quantidade de números pseudo aleatórios gerados na simulaçáo de cada pequena amostra, foi utilizado o máximo de 1000 números distribuídos pelos estratos dimensionados pela quantidade de elementos de cada pequena amostra, mostrando ser adequado para as avaliações realizadas.

Mesmo nas pequenas amostras que apresentam um máximo menor que o máximo da amostra de referência apresenta capacidade de identificar a produtividade do processo analisado, como no caso da simulação da pequena amostra 15elMAG.

O máximo de produtividade do processo, lido na cota de $100 \%$, é um valor mais otimista, pelo fato de necessitar de um valor menor de $\mathrm{Hh}$ para a realização da tarefa.

Quando se avalia a produtividade de um processo de soldagem em $\left[\mathrm{cm}^{3} / \mathrm{Hh}\right]$, a FPA obtida representa um valor percentual mínimo, passando pela média, mediana, moda, não necessariamente nesta ordem, até o valor que corresponde à produtividade máxima.

A produtividade na cota $90 \%$, da amostra de referência 52elMAG, está entre a informação fornecida pela simulaçáo da amostra 20elMAG e as outras duas amostras, 15elMAG e 10elMAG.

Observando-se a variaçáo entre as cotas de $100 \%$ e, por exemplo, 95\% verifica-se uma grande diferença nos valores de produtividade. Assim, é uma boa prática observar a variação da produtividade nas cotas 100\%, 95\%, 90\% e 50\% e avaliar a variação entre seus valores, para melhor tomada de decisão a respeito de qual valor utilizar como referência para dimensionamento da produtividade do processo.

A avaliação do gráfico da FPA permite obter o grau de incerteza na adoçáo de cada um destes critérios: produtividade média, pessimista e otimista. Assim, a probabilidade de ocorrência de produtividade inferior, referente à cota 90\%, tanto nas curvas geradas por simulaçáo, quanto na amostra de referência, é de $90 \%$, razão pela qual 
se trata de uma estimativa otimista do processo em questão. Ao analisar as curvas geradas por simulação e as amostras 15elMAG e 20elMAG, as que apresentaram melhor aderência com o universo considerado, em relação a amostra de referência, se observa que o valor da produtividade média se situa na altura da cota de 70 a $80 \%$. Assim, ao adotar o critério de produtividade média, que é o mais usado pela indústria, a probabilidade de ocorrência de valores de produtividade inferiores esta entre 70 a $80 \%$, aproximando este critério da condição mais otimista. Neste sentido, estes resultados revelam que uma boa prática na elaboração de estimativas de produtividade é considerar as possibilidades das probabilidades de ocorrência para valor adotado segundo a FPA, avaliando-se, em cada situação, a opção escolhida e o grau de incerteza que a mesma representa. Esta proposição é diferente da utilizada pela indústria atualmente, que baseia suas estimativas de custo, prazo e orçamento no critério da produtividade média retratada em condiçôes históricas.

Neste contexto, as estimativas para controle da produtividade ficam mais bem definidas tendo em vista a identificação da estimativa de produtividade otimista, da média e da pessimista, conforme mostrado pela Tabela 12 .

Tabela 12: Cenários de Produtividade do Processo de Soldagem MAG $\left[\mathrm{cm}^{3} / \mathrm{Hh}\right]$

\begin{tabular}{|l|c|c|c|}
\hline Referência & $\begin{array}{c}\text { Otimista } \\
(\mathbf{9 0 \%} \text { FPA) }\end{array}$ & Média & $\begin{array}{c}\text { Pessimista } \\
\text { (mínimo) }\end{array}$ \\
\hline 52 elementos & 93.00 & 40.81 & 0.84 \\
\hline $\begin{array}{l}\text { LHS 20 } \\
\text { elementos }\end{array}$ & 80.00 & 51.17 & 0.88 \\
\hline $\begin{array}{l}\text { LHS 15 } \\
\text { elementos }\end{array}$ & 100.00 & 43.23 & 3.97 \\
\hline $\begin{array}{l}\text { LHS 10 } \\
\text { elementos }\end{array}$ & 103.00 & 63.60 & 1.76 \\
\hline
\end{tabular}

\section{CONCLUSÃO}

Pelos resultados apresentados, verifica-se a aplicabilidade da simulação pelo método de $\mathrm{Hi}$ percubo Latino na avaliaçáo da produtividade do processo de soldagem elétrica MAG, nas condiçôes de coleta apresentadas, aplicado à montagem de tubos, com base em pequenas amostras. Isto fica demonstrado pela aderência das amostras geradas por simulação, com base em pequenas amostras, em relação à amostra de referência 52elMAG, que representa o universo do processo. Tal fato é de importância fundamental para a monitoração da produtividade da soldagem durante um empreendimento, pois, permite uma monitoraçáo periódica em intervalos de tempo curtos e eventuais correçóes de rumo, com objetivo de assegurar cumprimento de prazos e orçamento da obra, que podem ser realizadas durante sua execução. Atualmente, sabe-se que esta não é uma prática usual, tanto por parte das empresas de construção e montagem, quanto pela contratante, nas atividades de fiscalização de obra. Usualmente, utiliza-se um valor de produtividade média antes da execução da obra, a qual somente é aferida após a conclusão do empreendimento.

No que diz respeito a estimativas de produtividade na elaboração de orçamentos, projeçóes de prazo, ajustes de prazo e custo, entre outras, o método permite uma análise mais abrangente das probabilidades de ocorrência da produtividade pela análise das FPA geradas por simulação e pela possibilidade de adoção de estratégias mais diversificadas, sendo que se sugerem, neste trabalho, os critérios de produtividade média, pessimista e otimista.

Esta estratégia é substancialmente diferente da atualmente utilizada. Neste sentido, amplia-se a capacidade de acompanhamento e de tomada de decisão sobre qual indicador de produtividade utilizar.

\section{REFERÊNCIAS BIBLIOGRÁFICAS}

ANZANELLO, J. M.e FOGLIATTO, F. S. “Curvas de aprendizado: estado da arte e perspectivas de pesquisa". Escola de Engenharia, Departamento de Engenharia de Produção, Universidade Federal do Rio Grande do Sul - UFRGS. Porto Alegre, RS. p109-123. Jan, 2007.

AWS - American Welding Society. Welding - Related Expenditures and Productivity Measurement in U.S. Manufacturing, Construction, and Mining Industries. 2002. 90 p.

BESTFIT - Palisade Corporation - Distribution Fitting for Windows, v.4.5, (2004). 119 p. 
BRITO, J. D e PARANHOS, R. .P. R., "Como Determinar os Custos da Soldagem”, Ed. Paranhos, (2005).

COCHRAN, W. G. (1954), "The combination of estimates from different experiments". Biometrics, 10, 101-129.

CONSTÂNCIO, D. S.; FERREIRA, M. L .R. e FREIRE I. J.. Estimativa de "Produtividade na Soldagem de Tubulações Industriais utilizando o Método de Monte Carlo". XXXV CONSOLDA - Congresso Nacional de Soldagem; ABS - Associação Brasileira de Soldagem. Piracicaba, São Paulo, Brasil. 2009.

DIEKMANN, J. E. e HEINZ, J.. “Determinants of Jobsite Productivity: CII - Construction Industry Institute Research Rep". No. 143-11, Univ. of Texas at Austin, (2001). 144 p.

FLANAGAN R. e NORMAN, G. "Risk Management and Construction”. London, Blackwell Science, 208 p, (2003).

GIOIA A. L. S. ; SILVA JUNIOR, I. F., FERREIRA, M. L. R.; LANNES, D. P.; MAIA M. P. e PARDAL, J. "Avaliação da Metodologia da Produtividade na Atividade de Montagem de Tubulaçóes em Obras Industriais", 10 COTEQ ABENDE, Salvador, (2009).

MARTINS J. L. F., FERREIRA M. L. R. e SARAIVA, J. M. F. "Estimativa da Produtividade em Soldagem pelo Método de Monte Carlo”, Soldagem \& Inspeção, 16, 03, 204-212, (2011).

MARTINS, J. L. F. e FERREIRA, M. L. R. "Avaliação da Produtividade do Processo de Soldagem de Eletrodo Revestido através de Simulaçáo pelo Método do Hipercubo Latino". X Congresso Ibero-Americano em Engenharia Mecânica - CIBEM 10, 3579 - 3588, Porto, Portugal, 4 a 7 de Setembro (2011).

MARTINS, J. L. F. ; FERREIRA, M. L. R.; PARDAL, J. M. e MORANO, C. A. R. "Comparación de la estimación de la productividad Del proceso de soldadura eléctrica por los métodos de simu- lación de Monte Carlo e Hipercubo Latino". Información Tecnológica. 23(4), en prensa (2012).

MASCHIO, C.; CARVALHO, C. P. V. e SCHIOZER, D. J. "Aplicação da Técnica do Hipercubo Latino na Integração do Ajuste de Histórico com a Análise de Incertezas". 50 Congresso Brasileiro de Pesquisa e Desenvolvimento em Petróleo e Gás, Associação Brasileira de P\&D em Petróleo e Gás - ABPG, UFC, Fortaleza-CE, Outubro de 2009.

MATHWORKS. "MATLAB - The language of technical computing. Using MATLAB". Ver.6. The MathWorks, Inc. Natick, MA, USA. 2001.

MATHWORKS. "Statistics Toolbox ${ }^{\mathrm{TM}}$ 6. User's Guide”. The MathWorks, Inc. 2007.

MORANO, C. A. R. e FERREIRA, M. L. R. "Aplicação do Método de Monte Carlo em Análise de Riscos em Projetos de Construção". XXXV SBPO - Simpósio Brasileiro de Pesquisa Operacional, Natal, (2003a).

MORANO C. A. R. e FERREIRA, M. L. R. "Metodologias de Gerenciamento de Risco em Projetos”. Engevista (UFF), 53 - 65, Niterói, Rio de Janeiro, Brasil., 10 jun (2003b).

PAGE, J. S. e NATION, J. G. "Estimator's Piping Man Hour Manual”. First Revision, Gulf Pub Comp. Houston, Texas, (1967).

PILGER G. G, COSTA, J. F. C. L. e KOPPE, J. C. "Improving the Efficiency of the Sequential Simulation Algorithm Using Latin Hypercube Sampling”. Geostatistics Banff 2004, 14, Springer, 989-998, (2005).

PROMINP (Programa de Mobilização da Indústria do Petróleo e Gás Natural). Projeto E\&P 27.5 - Métricas de Desempenho da Indústria Nacional, Padróes de Métricas da Indústria EPC Nacional, (2010).

TRIOLA, M. F. Introdução à Estatística. 7a. Ed. Rio de Janeiro: LTC, (1999). 